\title{
Pre-Service Teachers Confronting and Examining Media Bias
}

\author{
Natasha C. Murray-Everett \\ West Virginia University \\ U. S. A. \\ Dorian L. Harrison \\ The Ohio State University at Newark \\ U. S. A.
}

ABSTRACT: This paper examines how pre-service teachers (PSTs) come to understand the role that media plays in perpetuating and reinforcing stereotypical views of marginalized groups through engagement in weekly news groups. This study sought to look at how critical media skills influenced the ways PSTs interacted with media content. Findings suggest that by critically engaging in controversial current event topics that participants began to recognize the value and importance in finding multiple and reliable sources. They also began to question and interrogate the problematic ways that race and racism are portrayed in and through the media.

\section{KEYWORDS: Critical race media literacy, bias, pre-service teachers, news}

\author{
Literature Review \\ Methodology \\ Findings \\ Discussion and Conclusion \\ References \\ Author Contact
}

Previous studies of media literacy have revealed that pre-service teachers (PSTs) are often unengaged with news media, even though the twenty-first century is technologically saturated (Cherner \& Curry, 2019). PSTs' engagement with news content usually involves casually scrolling a trending Tweet or Facebook headline, and the content they read and watch is often reflective of their own perspectives. "The influential role media plays in organizing, shaping, and disseminating information, ideas and values is creating a powerful public pedagogy" (Kellner \& Share, 2007, p. 59). As future educators, PSTs need to become more conscientious and critical of the news that they consume in order to become more informed, and consequently, to help their future students become informed citizens and active participants in a democracy. However, students are not often provided with opportunities to critically engage and critique the news they consume (Hess, 2004) and have fewer opportunities to discuss issues of race and equity (Pimentel \& Busey, 2018). Teachers and teacher educators have the added responsibility to provide their students with critical media skills so that they can 
interrogate media messages they receive. Doing this requires PSTs to interrogate the reciprocal effects of the media on their lives and the greater society.

In 2009, the National Council for the Social Studies (NCSS, 2016) provided a position statement towards critical media literacy $(C M L)$. Since that time, a number of studies within social studies teacher education found benefits for PSTs exposed to CML practices. CML provides pre-service social studies teachers with skills to recognize and critique controversial issues that exist in media and extends democratic pedagogical approaches.

CML, defined as the analysis of news and media resources, has the power to provide PSTs with valuable skills. Research on the impacts of CML in social studies teacher education has investigated the ways PSTs learn to focus on controversial topics (Hess, 2009; Ho, et al., 2017) and fake news (Kavanaugh \& Rich, 2018; Mason et al., 2018). Additional studies within and beyond teacher education have paid particular attention to the ways individuals recognize bias within the media and bias within themselves (Babad et al., 2012; Domonoske, 2016; Stoddard, 2009). Looking specifically in social studies education, controversial issues are not new to the field (Ho et al., 2017; Journell, 2011; LeCompte et al., 2017), and continue to be on the forefront of recent studies within the field. According to Hess (2009), controversial topics are largely based around political issues, but social studies teachers are likely to avoid these topics (McAnulty, 2020). Because Hess and McAnulty focus on the connections between democratic pedagogy and practice, discussions of controversial (political) issues serve to enhance students' democratic thinking. A primary issue in teaching controversial topics is the way teachers disclose their own views on issues (Hess, 2005; Kelly, 1989; Stoddard, 2009) or share their perspectives as fact. For example, when teachers pre-select topics that their students will discuss, they may influence their students' beliefs about issues that are important (Hess, 2004; Stoddard, 2009) or deemed as controversial (Journell, 2011). More often than not, social studies teachers are less informed about the positions they adopt concerning controversial issues and current event topics (McAnulty, 2020).

While there are benefits to $C M L$ approaches, educators have conflicting perspectives of the mass media and how it should be taught, which directly impacts pedagogical approaches to instruction in the classroom (Hobbs, 2004). In addition, teachers have historically avoided discussions of race and marginalization within their classrooms (Hess, 2004; King, 2017; McAnulty, 2020). These hesitations may help to explain why pedagogies that include discussions of controversial topics impacting marginalized or underrepresented groups are not prevalent in classrooms. With the contentious 2020 United States presidential election, we saw a greater need to focus on controversial topics and ways PSTs become accustomed to leading discussions, staying up to date, and investigating political issues. In particular, the intersections of race, class, citizenship status, and gender are key political discussions that have and will continue to impact our democratic discussions of politics (Journell, 2011), but in what ways and with what resources can teachers add this to their teaching agenda? 
Pulling from earlier studies of CML and controversial topics, we seek to address the lack of research focused on critical race media literacy (CRML) in social studies teacher education. Though CML skills are useful in broadly addressing bias in the media, deepening PSTs' analytical skills, and developing informed citizens (Kellner \& Share, 2007), this study explicitly centers race through CRML approaches. CRML was used as a framework in this study as it provides a series of skills and practices for helping direct PSTs' attention to the ways racist ideologies are embedded within media and institutions. By implementing this pedagogical approach, CRML supports the proposition that interacting with news and media content can lead to actionable critical steps to read and understand the world (Freire, 1985). Students are tasked with critically analyzing relationships between their funds of knowledge (Moll et al., 2006) and the information presented to them through media streams (Yosso, 2002; Entman \& Gross, 2006). In addition, $\mathrm{CRML}$ calls for students to examine the problematic ways that race and racism are portrayed in and through the media.

In this study, CRML practices were embedded in news groups, an instructional strategy used in an undergraduate social studies methods course. News groups required PSTs to find news sources on a current and controversial topic from multiple perspectives and engage in critical dialogue with their classmates. This pedagogical strategy attends to Hess's (2004, 2005) recommendation that students need to take part in discussions about controversial subject matter in order to enhance their democratic thinking. Additionally, news groups provided PSTs an opportunity to develop CRML skills; skills that are needed to analyze the media for bias and to recognize the ways that narratives are constructed.

\section{Literature Review}

Within this review of the literature, we discuss the impacts of CRML. It is important to note that there are studies of CML in social studies education; however, a focus on issues that underrepresented groups face are not always planned and are disregarded depending on the PSTs' comfortability with the topic. For these reasons, we find representation should be acknowledged and actively presented in democratic pedagogical approaches through what is now termed critical race media literacy (CRML).

\section{A Focus on Race}

In our search for CRML studies in social studies teacher education programs, we did not find explicit studies specifically citing CRML. In this section, we instead present a synthesis of information on CRML in education while also highlighting key studies.

CRML studies focus on the role media takes in perpetuating stereotypes and ideologies of marginalized and underrepresented people and institutional systems of oppression (Baynes, 2002; Bergstrom et al., 2018; Dixon, 2008; Entman \& Gross, 2008; Joanou, 2017; King 2017; Yosso, 2002). While still 
focusing on analysis, CRML moves beyond the development of informed citizens and calls for further analysis of the lived experiences of marginalized populations. Pre-service social studies teachers may not encompass a wealth of knowledge about marginalized groups or histories of oppression, and as such, the first steps in CRML involve developing a critical awareness of media (Torres \& Mercado, 2006). Similar to CML approaches, critical awareness and recognition provides learners with a starting point for discussions around controversial issues.

King (2017) argued that the news media is a project maintained through society's racial apparatus that preserves racial hegemony and stratification. The unconscious/conscious strategies of transmission are often lost on uninformed consumers of the media, especially as it relates to biases towards particular racial and ethnic groups. King (2017) further argued that the U.S. news media transmits the cultural representations of people, and in many cases Black people, which aligns with socially constructed norms of race. This understanding of perpetuated messages of difference could unconsciously or consciously impact the ways consumers of media engage with others and how we understand society.

Living in a media-saturated world, a pedagogy that helps PSTs learn to question the use and function of media and its messages on various cultures could serve to further their understanding of democracy and democratic practices (Gainer, 2007, 2010; Higdon, 2017; Kellner, 2013; Kellner \& Share, 2005). Agosto et al. (2014) utilized examples of racial incidents and depictions of Black people through the media with a group of faculty and graduate students in teacher education. Their CRML approach involved providing clear depictions of inequity in action. The researchers used pre-selected media footage for participants to discuss and analyze during a retreat. At multiple times, researchers observed their participants justifying the decisions made in videos or captured within images. These moments of justification highlight the ways racism and inequity have become embedded within individual thinking and institutional knowledge. CRML, therefore, must include close observations of classroom discussions, reflections, and the ability for the instructor to provide conceptual understandings which include power, domination, and racism.

Pennell (2019) argued that the scaffolding of appropriate practices and activities paired with critical analysis helps classroom teachers see themselves using these approaches. If not, teachers and PSTs often offset discussions of race to reading and language disciplines, instead of a discussion that should be happening across disciplines including social studies (Agodzo, 2016; Marshall et al., 2016). Scholars have also observed moments when educators chose to ignore race in their observations of media and stereotyped depictions of marginalized populations (Agosto et al., 2014), moments of avoiding discussions focused on race or racism due to a lack of knowledge or experience with the topic (Mills \& Unsworth, 2018) in favor of more palpable approaches to instruction (Pimentel \& Busey, 2018). However, as cited earlier, democratic approaches invite controversial topics into guided discussion in an effort to hear new positions and experiences, and to develop informed positions on topics and issues. By taking and embedding these ideals, CRML calls for us to consider "racially constructed 
norms" (King, 2017, p. 38) in media, how racialized messages carry certain knowledge about marginalized communities, and how PSTs unconsciously and consciously frame their teaching around media messages.

In this paper, we are concerned with the need for CRML in social studies teacher education and for it to be taken up as an extension of controversial topics and CML (Yosso, 2002), which are already well documented in social studies education. By emphasizing democratic structures of instruction in social studies we assert that race and media depictions of race already exist and need to be more explicitly approached and discussed. This study takes a pedagogical look at how one university social studies instructor implemented a CRML project across multiple semesters.

\section{Methodology and Course Context}

This year-long qualitative study was conducted at a large, semi-rural, landgrant institution with 80 elementary education majors taking an undergraduate social studies methods course. In this course, PSTs engaged in social studies disciplines such as history, geography, civics, and economics through a justiceoriented lens where conversations about race and controversial topics were the norm. This specific study focused on the pedagogical approach of news groups and PSTs' coursework products gathered post instruction. As a result, informed consent was not required due to minimal risk and data were considered educational records and deemed archival data collection.

\section{News Groups}

News groups, developed by the first author and instructor of the course, were one of the projects that PSTs completed throughout the semester where they engaged in a controversial current event topic relevant to the United States. The content from this project formed the data for this study. The purpose of the project was to have PSTs (1) read and engage with current media, (2) fact check stories that they found and read, (3) recognize biases inherent in the media, (4) become more competent discussing controversial issues with classroom peers, and (5) consider the ways they may engage their future students in similar news groups (Murray-Everett \& Coffield, 2020).

News group topics between 2018-2019 included racial protesting and/or police brutality, gun control, immigration, teacher activism, the Russian investigation (which looked into how Russia impacted the 2016 presidential election), border security, local and state current events (e.g., foster care, opioid crisis, teacher strikes), and political elections. The instructor, also referred to here as the teacher educator, shared potential current news group topics but also provided PSTs an opportunity to offer topics that they found interesting or wanted to know more about (i.e., teacher activism/teacher strikes). The teacher educator then had the PSTs rank their individual choices for topics and placed them in one of five or six groups (depending on the class and the semester); PSTs were always placed in one of their top three choices. Unlike traditional descriptions of 
controversial topics in pre-service education (Hess, 2004), the teacher educator did not facilitate whole group discussions about the group topics due to time constraints and because the PSTs each presented their work at the end of the project, which was space dedicated to whole group discussion. Groups independently worked to learn more about their topics through media searches of news reports. The groups gathered related media sources (videos, online news articles, tweets, etc.) that argued multiple sides of their topic, and PSTs placed them in a shared Google document for their group and instructor to view. PSTs met in their news group each week for 15-30 minutes during class to share and discuss their findings. Here is where the teacher educator circulated between the groups and joined in the discussion. Their investigation included finding multiple perspectives and seeing bias (e.g., political and racial awareness) inherent in media content. As part of the project, PSTs had to present their findings to their classmates at the end of the semester. After they completed the group presentation, they each wrote an individual reflection paper on the totality of the experience.

\section{Participants}

Participants were undergraduate students (PSTs), juniors and seniors, majoring in elementary education. Of the 80 PSTs, all but four PSTs identified as female, the remaining four identified as male. Racially, 78 PSTs identified as White, one as Back, and one student identified as Spanish. While many of the PSTs were from the state that the institution served, a number were from neighboring states that had different political and racial climates, and thus PSTs' understanding and experience with issues of politics and race varied. For this project, we focused specifically on the course data collected from 34 PSTs who participated in news group topics that dealt specifically with issues related to class, race, and immigration.

\section{Authors' Positionality}

Author one is the social studies methods instructor for the courses referenced in this study; author two, a literacy scholar, brings a strong background in critical literacy research. We both identify as Women of Color and have a commitment to justice-oriented teaching and scholarship. Our K-6 teaching experience has been primarily with Black and Brown elementary students in suburban and urban communities. Now, as teacher educators, working with predominantly White PSTs over the last nine years, we find it vital to center the teaching of race in our pedagogy, something that was largely missing from our own teacher education experiences. Within our specific disciplines of social studies and literacy education, we do engage PSTs in justice-oriented work through the texts that we choose for the course, the assignments we assign, and the discussions we have in class. As Black women, we see how our histories have been written for us and how media portrayals of race often go unnoticed for our White PSTs. This can be problematic when many come to teacher education programs with 
misinformed views and perspectives of the Students of Color they will teach. As such, we hope that by engaging PSTs in social studies and literacy pedagogical methods they will examine the role media plays in shaping these racialized narratives.

From the onset, the first author of the study did not initially and explicitly state her stance about the news group topics that were selected until after presentations. She recognized that, even at a university, she was in a position of power, and while the research suggests the positives of sharing instructor perspectives, she acknowledged that news groups were part of a larger graded assignment and that doing so may have silenced those who had different opinions. That said, it must be noted that, while one may not explicitly share their stance on an issue, they do so in other unspoken ways. For example, the syllabus for this course centered the experiences of People of Color through the course texts and readings; the course calendar listed topics such as social justice, anti-bias and anti-racist education; the instructor discussed the importance of Black Lives Matter and its pertinence to $\mathrm{K}-12$ education and shared the importance of discussing race in the elementary classroom. These may have clued PSTs in on her position on these specific news group topics and potentially influenced how they presented their group projects. That said, PSTs had to highlight the multiple perspectives conveyed through the news in their final presentation.

\section{Data Sources}

Table 1 below shows the news groups topics. These topics included racial protesting and/or police brutality, immigration, and border security. At the time of the study, these topics were deemed as controversial because they embodied multiple points of view to be deliberated amongst PSTs (Hess, 2009; Journell, 2011).

Table 1

News Groups Fall 2018 \& Spring 2019 Immigration Border Security Racial Protesting Police Brutality

Fall 2018

Spring 2019

(Section A)

Spring 2019

(Section B)
$\mathbf{X}$

$\mathbf{X}$

$\mathbf{X}$
$\mathbf{X}$

$\mathbf{X} \quad \mathbf{X}$

Drawing from PSTs' assignments, a variety of qualitative data was collected including: (1) news group materials for the four selected topics (shared Google documents and final group presentations) and (2) individual reflection papers for PSTs within the selected topics. All PSTs work was de-identified with a 
pseudonym. Each week, PSTs had to find news and media content and upload them to their groups' Google document. Their final group projects drew upon these weekly findings and included media presentations (i.e., PowerPoint, GoogleSlides, or Prezi presentations) that were uploaded to the course site. These presentations illuminated how the PSTs collectively worked to understand ways the news was portraying their racially informed topics, an analysis of bias across news sources, and if their sense of competency about the topic developed throughout the semester. The individual reflection papers provided insight to how working in news groups influenced how PSTs thought about news and media content (i.e., media bias, perspectives, political agendas). The instructor's knowledge of the way the groups worked to locate resources and their weekly discussions shed light on the ways PSTs grew in their awareness of the topics and critical approaches toward understanding the information.

\section{Data Analysis}

Content analysis methods were first used to look across texts, images, and other symbolic matter (Krippendorff, 2004) presented by the news groups. The use of content analysis helped reveal the frequency of concepts related to controversial topics within student reflection data. For this analysis, broad themes were drawn from the word, phrase, and sentence levels (Brooks \& King, 2012). We then looked at the frequency of the terms/words across each of the news groups and analyzed the meanings of the relationships between topics to better understand the impacts of engaging with controversial topics through CRML guided news groups.

Next, the reflections were read by each author several times as part of emergent coding (Blair, 2015; Stemler, 2001). Individual reflection papers were analyzed for patterns and trends to determine what, if any, new learning PSTs walked away with after the course, if their experience engaging in news content was meaningful, and how they might consider using news groups in their future teaching. Lastly, the authors separately looked across all codes and compressed them into content categories based on explicit rules of coding while coming to a consensus on themes for the paper (Stemler, 2001).

\section{Findings}

Before exploring the ways PSTs discussed and reflected upon the controversial topics, we present a summary of their overall approach to the controversial topics captured in their written reflections. Through both sections of the course, there were a total of three groups focused on immigration, two groups focused on border security, one group focused on police brutality, and two groups focused on racial protesting. Utilizing Entman and Gross's (2008) exploration of their students' work, we present the analysis of the content (see Table 2) within the PSTs' reflections as they pertain to discussions of race, class, bias, and politics. Four descriptive categories were used across the controversial topics. We looked for evidence of explicit references to particular terms as evidence of PSTs' 
attention to racial and ethnic issues within the media. The data in Table 2 shows the total number of comments that were observed from the documents and the percentage as it relates to the whole category.

Within these discourse patterns we noticed that groups with racialized language (immigration and racial protesting) were more likely to engage in discussions of race and politics in comparison to the other two groups (gun control and police brutality). Immigration, border security, and racial protesting groups keyed in on the political arguments that were being made across media outlets regarding their topic. But only one of the groups (immigration) showed a clear connection between the media's arguments and the biased descriptions that were also present.

\section{Table 2}

Reflections with Racial Bias and Class Bias References

$\begin{array}{llllc}\text { Immigration } & \text { Border } & \text { Police } & \text { Racial } & \text { Total } \\ (3) & \text { Security } & \text { Brutality } & \text { Protesting } & \text { Comments }\end{array}$

(2)

(1)

(2)

Reflections in

which the terms

liberal,

conservative,

politics,

republican, democratic, neutral, government, agenda, left wing, or right wing appear

Reflections in which the terms bias, viewpoint, skewed, belief, portrayal, or prejudice appear

16

$41.02 \%$
1
9

39

\section{$33.33 \% \quad 2.56 \% \quad 23.07 \%$ \\ $33.33 \% \quad 2.56 \% \quad 23.07 \%$}

28

10

8

9

55

$50.9 \% \quad 18.18 \% \quad 14.54 \% \quad 16.36 \%$ 

Reflections in
6
1
2
2
11
which the terms
class, privilege,
$54.54 \%$
$9.09 \%$
$18.18 \%$
$18.18 \%$
suburban, poor,
working class,
poverty, old,
young, or welfare
appear
Reflections in
which the terms
10
4
23
92
race, ethnicity,
$59.7 \% \quad 10.8 \% \quad 4.3 \% \quad 25 \%$
minority,
immigrant, African
American,
Hispanic, Latino,
white, black, or
migrant appear

Adopted from Entman and Gross (2008)

The patterns observed in the chart above matched other studies of the ways practicing teachers confront racialized topics within their classrooms (Journell, 2011) and led us to look closer at the ways PSTs discussed topics and how they were learning to do CRML through racialized controversial topics. Below we explore three themes that connect back to this chart and illustrate how PSTs did or did not successfully engage in CRML: (1) digging deeper: finding accurate information; (2) valuing confrontations of controversial topics; and (3) confronting and examining media bias.

\section{Digging Deeper: Finding Accurate Information}

A constant thread woven throughout the themes was digging deeper to "uncover the true story about what happened and what is happening in America and across the world" (Taylor, written reflection). Many PSTs stated that it was difficult to find information that was factually accurate because much of the content they read was more so "entertainment media" (Yosso, 2002) that skewed representations of marginalized groups. Working in their news groups challenged them to seek out different networks and sources of information on the same story in the pursuit of finding factual and accurate information. PSTs mentioned they started fact checking the sources they were reading by seeking out multiple news sources. Nicole said: "... a direct example of this is reading or watching a news story from CNN and Fox, and then fact checking them against additional national sources that are recognized as more balanced like NPR." Cable News Network (CNN) and Fox News are politically polarized national news sources in the United States, while National Public Radio (NPR) is recognized as a more credible news 
source. While NPR is not a fact checking website, PSTs did come to recognize that NPR was a more balanced news source and thus, the percentage of its content was more accurate than other news sources (e.g., Fox News). Further, PSTs were given fact-checking websites as well as the media chart bias chart (mediabiaschart.com) to check the accuracy and the political slant of some of the content they came across.

Similarly, when talking about immigration, PSTs consistently reported having to dig deeper in order to find reliable information. Courtney shared that she needed to be more critical about how the media portrays immigration and found that through the project she noticed herself looking for "more unbiased news sources and really investigated sources like NPR." In her analysis, she learned that "people are actually staying in the United States illegally via expired visas and not through sneaking through the Southern border as it is portrayed through the media." Ainsley, another student in an immigration news group, expressed frustration that many "sources were more concerned with looking at a person as a source of the issue, instead of looking at the issue objectively. This made it difficult to find actual facts about the topic that were somewhat objective."

PSTs recognized that they needed to support the information they received with evidence, allowing them to have a more informed perspective.

I was amazed at how the same story can be presented in so many different ways just based on what site you're on. This has caused me to be very careful of where I am getting my information from. I want to look for sites that have more factual information, not opinions from different sites. If I want to be truly informed about these issues in the world, the best way for me to do this is to find sites that present the information so that I can make my own informed decisions. (Michelle, written reflection)

The PSTs highlighted the work that came with finding accurate information. "I run many more checks and follow up on what is being said to find out the other sides of the story," said Nia. This notion of digging deeper became a constant refrain throughout the findings and allowed PSTs to value confronting controversial topics as well as to examine the presence of media bias and bravely consider race and class as they are depicted in the media.

\section{Valuing Confrontations of Controversial Topics}

We looked at the ways PSTs discussed their confrontations with their topics and the journeys they took to find reliable information that may or may not have matched with their perspectives. As the PSTs developed their critical analyses of the media, they also thought about the media's impact on themselves and on their future classrooms. Liza, a member of the immigration group, described her stance at the beginning of the project. 
Before completing this project, I had mixed feelings about immigration. I did not really understand what was going on with immigration other than there were people who were coming here illegally, but I did not really know why they were coming here. I will admit that I was one who was wondering why undocumented immigrants did not just come here the legal way. (Liza, written reflection)

Liza then further unpacked her initial position on immigration upon entering the class. After 4 months of critical analysis and reflection, she stated, "I do believe my research on immigration and listening to the testimonies of my peers have given me an extra lens to apply when reading the news." Value was not only found through self-reflective revelations. PSTs also found they were able to challenge previously held notions influenced by their families. According to Jillian,

I started off this class very uncomfortable talking about controversial topics because I was raised to believe it is impolite to talk about politics (controversial matters) at the dinner table. Throughout the course of this class, I have grown more comfortable which made this project easier to do. (Jillian, written reflection)

Another PST stated,

I remember when the DREAM Act was first put into action, my parents were angry and upset. When they told me that it allowed the government to take children who were in the country illegally and give them a bunch of money in scholarships, welfare, and more, I took my parents' word for it, and never really thought much of it. However, because of this project, I learned that what I was told was entirely false. I even got into an argument with my very stubborn father about immigration news bias. (Monica, written reflection)

What Jillian and Monica found was value in the voices they were able to give to this controversial topic by critically examining the biases in the news and then advocating for truer narratives. Monica being able to talk back to her father shows how she became empowered once she gained critical awareness and factual insight.

Based on revelations such as this, it was evident that PSTs were not only braving discussing topics that were controversial, they were also valuing growth as they learned to read the world around them (Freire, 1985). "I've also learned to try and place myself within that situation before passing judgement because every interaction is unique and must be looked at more critically" (Camila, written 
reflection). Ben also added, "I think that this was a valuable project and forced us to step out of our own beliefs about a topic and really look at all the perspectives and sides of the stories." Although this research has shown ways that PSTs learn to critically examine the media and what they read and advocate, we also learned that the PSTs found the most value in the examination process. By challenging their understanding of their topics, they developed valuable strategies for becoming more informed consumers of the news media.

\section{Confronting and Examining Media Bias}

The major finding in this study was related to the PSTs' awareness of media bias within the news. Yosso (2002) argued that students' motivation to change societal perceptions were strengthened and encouraged through their confrontations with inequities in the news. In like manner, the PSTs within the news groups presented heightened levels of awareness in their own examinations of bias within media representations of marginalized groups. Danielle, from the police brutality group, wrote:

When I was introduced to an idea, I only looked first glance and never really thought about the person behind the voice telling the story. I'm definitely more aware of what is being presented to me and the biases that fall within it. I run many more checks and follow up on what is being said to find out the other sides of the story. (Danielle, written reflection)

Another PST also echoed a level of shock that news sources could contain high levels of bias. Whitney stated,

I had no idea the level of bias and manipulation that occurs on these [TV] channels. You would assume that because it's a news channel it has to be true, and that all news channels would say the same things. (Whitney, written reflection)

In some cases, the PSTs realized that they only consumed messages associated with particular political parties and ideas. First, they came to see the news as containing varied levels of bias. Lisabeth wrote, "Doing this [news groups] made me realize that when I do read articles, I am just reading ones that share the same viewpoint as me, only reinforcing my own thinking and not trying to understand the ways others think." Julie also recognized the polarizing coverage of the media and admitted that she too "had fallen prey to the pitfalls of a single perspective, my single perspective." Second, PSTs saw how they too made biased choices based upon their own interests. Avery noted, "Because of this [project] I realized that I needed to be aware of my own biases when it came to looking for reliable sources for this project." Emery added that, "Most people have a news 
channel of choice, which directly impacts the way they are being presented the information." These examples point to PSTs' realizations of their own perspectives with respect to the media and how their choices have influenced their views on the portrayals of racial and ethnic minoritized groups.

The biases that PSTs acknowledged they had in many ways was informed by the perspective that they noticed in the illustrations and from headlines causing them to be shocked and surprised that news and media are driven by varying agendas (e.g., political) and how headlines alone can skew one's perspective on an issue. Gina commented,

What shocked me the most from this project was how just the headline of an article can shape the readers view of a piece before they even begin to read it...If one bases their view off of just the headline, their conclusions may contain a lot of bias. That first impression of an article, whether in a newspaper or online can skew any readers' viewpoint on a topic was an insightful beginning. (Gina, written reflection)

While everything has bias, the PSTs highlighted that they were thinking critically about how bias is inherent in headlines or in articles. This kind of realization was not an isolated case. Another student explained that during the project she too learned a lot about social media and headlines.

Some of the headlines I read shocked me-even from the news outlets that present things from the point of view I agree with! I think we are entering a time where news media is under attack anyway by the current administration and news sources that do not take their roles as journalist seriously and instead present opinions as news are not helping the situation. (Kelly, written reflection)

The driving force behind this PST's understanding of biased headlines was grounded in biased political agendas thought to be non-partisan. However, the student mentions that there is bias, and they are recognizing the intersection of bias and media's overarching agenda.

These kinds of realizations are closely related to the other themes presented in this paper, but also speak to early realizations and confrontations with examinations of bias and examinations of narratives. The PSTs spent a lot of time learning about mainstream dominant narratives that privileged and centered White voices and experiences, often excluding those who have been marginalized. As such, Joyce so poignantly reflected, "I realized just how untrue the master narrative that we have all heard about is." Here she realized that a master narrative (Aleman \& Aleman, 2016) has been created about racial inequality. 


\section{Discussion and Conclusion}

When compared to previous studies of CRML, our findings present key differences in our participants and could be attributed to the interpretive differences PSTs made. For example, the PSTs were more likely to place blame on media institutions and position themselves as separate from the source of negative biases presented. However, previous CRML studies typically engage with participants who are members of marginalized populations who worked to challenge ideologies found in media (Yosso, 2002). In contrast, this study positioned predominately White PSTs with the task of analyzing, discussing, and recognizing biases present in media, while also searching for counterstories to the predominant messages being presented. These efforts of centering race through CRML have relevance for broader education venues. We argue that the use of news groups provided PSTs with a helpful way of seeing how race and other controversial issues are portrayed within the media and thus, the importance of considering multiple perspectives when researching events. Because the controversial topics are ones that impact the nation and multitudes of marginalized populations, it is transferable to other communities, outside of the context in which this study was conducted. Below we consider the ways PSTs chose to think and engage with news media, and what this may mean for teacher education faculty attempting to embrace CRML. Findings from this study match what scholars have suggested makes that an effective CRML approach: critical awareness of media (Torres \& Mercado, 2006; Yosso, 2002) and empowerment (Frechette, 2016).

\section{Race and Racism Must Be Explicit}

When considering PSTs' written reflections on issues of race, we recognized how some groups would disregard the racial themes presented within the media; how some groups chose more palpable language for their group topic; and more explicitly how race related to the instructor's positionality as a Black instructor. First, we noticed a difference in the ways that students reflected on racialized topics based upon the name of their group. Although each of the news groups in this study were presented with racially and/or class-based topics, some were less likely to identify the ways various racial groups experienced certain social issues. This was observed in some of the student reflections. In particular, naming various cultural groups became an important indicator of student awareness.

Next, we address the naming of groups. We found that the titles of the group topics in discussion were a surprising factor in the way PSTs engaged with racialized topics and discussions across each semester. In this occurrence, one group seemingly renamed themselves. The news group name was "police brutality" rather than the original title, "racial protesting." By changing the group name, PSTs' written reflections and group presentations focused on generalized brutality from police rather than examinations of biases and the impacts of the biases on marginalized groups in both their reflections and group presentations. 
This connects back to the purpose of CRML to examine issues of power and justice with a particular emphasis on race and racism. In this example, the PSTs enacted their power to subvert the racial discussions and provided an institutionalized lens on the issue by leading with police brutality rather than racial protesting and the histories behind these movements that involve the police. PSTs implicitly or explicitly, depending on how you understand their actions, perpetuated racist ideologies around discussions of race and investigations of race within the media.

In contrast, the two groups with direct racialized titles ("immigration" and "racial protesting") were more likely to directly discuss and write about the impacts the media had on the Black and Brown communities across the nation. However, the other groups ("border security" and "police brutality") engaged in political bias more so than the impacts of negative biases on marginalized groups of people. We question if the names of the news group topics created this difference since race was not explicit in the group title.

The lack of explicit attention to race mirrors what other researchers have discussed about PSTs' lack of comfort with controversial topics and topics of race (e.g., Hess, 2004; King, 2017; McAnulty, 2020). The PSTs in the border security and police brutality groups focused on general political biases that they noticed rather than an explicit attention to race. The police brutality group empowered themselves to change their focus from race to the institution. These observations highlight the need for continued conversations that center race and the need for instructors who can guide race and power-focused discussions.

The focus on instructor positionality during the news groups in relation to race must also be discussed. The instructor, author one, is a Black woman who sought to challenge her predominately White PSTs through critical analyses of media and critical discussions of race. She was intentional about engaging PSTs in conversations about race in the course, so that they could begin to understand the perspectives of those marginalized in history and in the present; this translated into news groups when she circulated among the news groups each week, often posing questions to each group. In these ways, race and difference were always present in the classroom environment.

We are encouraged by the power of news groups as an inquiry-based pedagogical tool. This study met the goals of incorporating controversial topics and CRML within the framework of a media literacy activity-news groups. We also recognize the process can be limited to a degree. As stated above, race could easily be overlooked within controversial issues unless it was explicitly stated. In drawing implications from this research for classroom instruction, we hoped to show that there is a need to include race within CML studies and that news groups are a practice that can facilitate those explorations. Overall, the reflections and presentations submitted by the PSTs demonstrated their ability to critically analyze media content and "see beyond themselves." This form of engagement with CRML is important for future educators, especially within the social studies, who are constantly engaged with media content that shapes how they view their world and their future students. 


\section{References}

Agodzo, D. (2016). Burying their heads in the sand: Critical race media literacy \& Surrey school district teachers. Multicultural Education, 24(1), 25-30.

Agosto, V., Karanxha, Z., \& Cobb-Roberts, D. (2016). Critical race media literacy and critical incidents of retreating to teachable moments. In N. N. Croom \& T. E. Marsh (Eds.), Envisioning critical race praxis in higher education through counter-storytelling (pp. 107-120). Information Age Publishing.

Aleman, S., \& Aleman, E. A. (2016). Critical race media projects: Counterstories and praxis (re)claim Chicana/o experiences. Urban Education, 51(3), 287314. https://doi.org/10.1177/0042085915626212.

Babad, E., Peer, E., \& Hobbs, R. (2012). Media literacy and media bias: Are media literacy students less susceptible to nonverbal judgement biases? Psychology of Popular Media Culture, 1(2), 97-101. https://doi.org/ 10.1037/a0028181

Baynes, L.M. (2002). Racial profiling, September 11th and the media: A critical race theory analysis. Virginia Sports and Entertainment Law Journal, 2(1), 1-62.

Bergstrom, A., Flynn, M., \& Craig, C. (2018). Deconstructing media in the college classroom: A longitudinal critical media literacy intervention. Journal of Media Literacy Education, 10(3), 113-131. https://doi.org/10.23860/JMLE2018-10-03-07

Blair, E. (2015). A reflective exploration of two qualitative data coding techniques. Journal of Methods and Measurement in the Social Sciences, 6(3), 14-29. https://doi.org/10.2458/v6i1.18772

Brooks, J., \& King, N. (2012). Qualitative psychology in the real word: The utility of template analysis. Paper presented at British Psychological Society Annual Conference, $18^{\text {th }}-20^{\text {th }}$ April, London, UK.

Cherner, T. S., \& Curry, K. (2019). Preparing pre-service teachers to teach media literacy: A response to "Fake News." Journal of Media Literacy Education, 11(1), 1-31. https://doi.org/ 10.23860/JMLE-2019-11-1-1

Dixon, T. (2008). Crime news and racialized beliefs: Understanding the relationship between local news viewing and perceptions of African Americans and crime. Journal of Communication, 58(1),106-125. https://doi.org/10.1111/j.1460-2466.2007.00376.x

Domonoske, C. (2016). Students have dismaying inability to tell fake news from real, study finds. The two-way. NPR. https://www.npr.org/ sections/thetwo-way/2016/11/23/503129818/study-finds-students-havedismaying-inability-to-tell-fake-news-from-real. 
Entman, R.M., \& Gross, K. A. (2008). Race to judgment: Stereotyping media and criminal defendants. Law and Contemporary Problems, 71(4), 93-133. Retrieved from http://www.jstor.org/stable/27654685

Frechette, J. (2016). Cyber-democracy or cyber-hegemony? Exploring the political and economic structures of the Internet as an alternative source of information. Library Trends, 53(4), 555-575.

Freire, P. (1985). Reading the world and reading the word: An interview with Paulo Freire. Language Arts, 62(1), 15-21. Retrieved from http://www.jstor.org/stable/41405241

Gainer, J. (2007). Social critique and pleasure: Critical media literacy with popular culture texts. Language Arts, 85(2), 106-114. Retrieved from https://www.jstor.org/stable/41962252

Gainer, J. (2010). Critical media literacy in middle school: Exploring the politics of representation. Journal of Adolescent and Adult Literacy, 53(5), 364-373. https://doi.org/ 10.1598/JAAL.53.5.2

Hess, D. (2004). Controversies about controversial issues in democratic education. PS: Political Science and Politics, 37(2), 257-261. https://doi.org/10.1017/s1049096504004196

Hess, D. (2005). How do teachers' political views influence teaching about controversial issues? Social Education, 69(1), 47-48. Retrieved from https://www.socialstudies.org/system/files/publications/articles/se_690104 7.pdf

Hess, D. (2009). Controversy in the classroom: The democratic power of discussion. Routledge.

Higdon, N. R. (2017). Effective critical media literacy pedagogy in higher education: Turning social justice theory into practice. [Unpublished doctoral dissertation]. San Francisco State University. https://search.proquest. com/docview/2150116447.

Ho, L., McAvoy, P., Hess, D. \& Gibbs, B. (2017). Teaching and learning about controversial issues and topics in the social studies: A review of the research. In M. M. Manfra, \& C. B. Bolick (Eds.), The Handbook of social studies research (pp.321-335). Wiley.

Hobbs, R. (2004). A review of school-based initiatives in media literacy education. American Behavioral Scientist, 48(1), 42-59. https://doi.org/ $10.1177 / 0002764204267250$

Joanou, J. P. (2017). Examining the world around us: Critical media literacy in teacher education. Multicultural Perspectives, 19(1), 40-46. https://doi.org $/ 10.1080 / 15210960.2017 .1267514$ 
Journell, W. (2011). Teacher's controversial issue decisions related to race, gender, and religion during the 2008 Presidential election. Theory \& Research in Social Education, 39(3), 348-392. https://doi.org /10.1080/00933104.2011.10473459

Kavanaugh, J., \& Rich, M. (2018). Truth decay: An initial exploration of the diminishing role of facts and analysis in American public life. Rand Corporation.

Kellner, D. (2013). Media spectacle and domestic terrorism: The case of the Batman/Joker cinema massacre. Review of Education, Pedagogy, and Cultural Studies, 35(3), 157-177. https://doi.org/10.1080 /10714413.2013.799364

Kellner, D., \& Share, J. (2005). Toward a critical media literacy: Core concepts, debates, organizations, and policy. Discourse Studies in the Cultural Politics of Education, 26(3), 369-386. https://doi.org/10.1080 /01596300500200169

Kellner, D., \& Share, J. (2007). Critical media literacy, democracy, and the reconstruction of education. In D. Macedo \& S. R. Steinberg (Eds.), Media literacy: A reader (pp. 3-23). Peter Lang Publishing.

Kellner, D., \& Share, J. (2009). Critical media education and radical democracy. In M. W. Apple, W. Au, \& L. A. Gandin (Eds), The Routledge international handbook of critical education (pp. 281-295). Routledge.

Kelly, T. E. (1989). Leading class discussions of controversial issues. Social Education, 53, 368-370.

King, L. (2017). The media and Black masculinity: Looking at the media through race[d] lenses. Critical Education, 8(2), 31-40.

Krippendorff, K. (2004). Content Analysis: An introduction to its methodology (2nd ed.). Sage.

LeCompte, K., Blevins, B., \& Ray, B. (2017). Teaching current events and media literacy: Critical thinking, effective communication, and active citizenship. Social Studies and the Young Learner, 29(3), 17-20. Retrieved from https://www.socialstudies.org/system/files/publications/articles/yl_2903171 7.pdf

Marshall, P. L., Mantra, M. M., \& Simmons, C. G. (2016). No more playing in the dark: Twenty-first century citizenship, critical race theory, and the future of social studies methods. In A. R. Crowe, A. Cuenca (Eds.), Rethinking social studies teacher education in the twenty-first century. Springer International Publishing.

Mason, L. E., Krutka, D. G., \& Stoddard, J. (2018). Media literacy, democracy, and the challenge of fake news. Journal of Media Literacy Education, 10 (2), 110. https://doi.org/ 10.23860/JMLE-2018-10-2-1 
McAnulty, J. (2020). Preservice teachers' perceptions of teaching news media literacy. Social Studies Research and Practice 15(1), 97-113. https://doi.org/10.1108/ssrp-11-2019-0054

Mills, K. A., \& Unsworth, L. (2018). The multimodal construction of race: A review of critical race theory research. Language and Education, 32(4), 313-332. https://doi.org/10.1080/09500782.2018.1434787

Moll, L., Amanti, C. Neff, D., \& Gonzalez, N. (2006). Funds of knowledge for teaching: Using a qualitative approach to connect homes and classrooms. Theory into Practice, 31(2), 132-141. https://doi.org $/ 10.1080 / 00405849209543534$

Murray-Everett, N. C., \& Coffield, E. (2020). News group Fridays: Engaging students in current events. Social Studies and the Young Learner, 33(2), 3-11. Retrieved from https://www.socialstudies.org/sites/default/files/viewarticle-2020-12/yl3302203.pdf

National Council for the Social Studies (2016). Media literacy. Social Education, 80(3), 183-185. Retrieved from https://www.socialstudies.org/socialeducation/80/03/media-literacy

Pennell, S. M. (2019). Reading representations of race: Critical literacy and Ferguson. English Journal, 108(4), 68-75.

Pimentel, C. N., \& Busey, C. L. (2018). Hollywood films as social studies curriculum: Advancing a critical media literacy approach to analyzing Black male representation. Critical Education, 9(4), 1-18.

Stemler, S. (2001). An overview of content analysis. Practical Assessment, Research and Evaluation, 7(17), 137-146. https://doi.org/10.7275/z6fm$2 \mathrm{e} 34$

Stoddard, J. D. (2009). The ideological implications of using "Educational" film to teach controversial events. Curriculum Inquiry, 39(3), 407-432. https://doi.org/10.1111/j.1467-873x.2009.00450.x

Torres, M., \& Mercado, M. (2006). The need for critical media literacy in teacher education core curricula, Educational Studies, 39(3), 260-282. https://doi.org/10.1207/s15326993es3903_5

Yosso, T. (2002). Critical race media literacy: Challenging deficit discourse about Chicanas/os. Journal of Popular Film and Television, 30(1), 52-62. https://doi.org/10.1080/01956050209605559

\section{Author Contact}

Natasha C. Murray-Everett, Natasha.murrayeverett@mail.wvu.edu Department of Curriculum and Instruction/Literacy Studies, Allen Hall 355 Oakland St, Morgantown WV, 26505 
Dorian Harrison, harrison.898@osu.edu

Department of Teaching and Learning, 184 Hopewell Hall, 1179 University Dr. Newark, $\mathrm{OH} 43055$ 